\title{
Moderasi Beragama dan Media Sosial (Studi Analisis Konten Instagram \& Tik-Tok)
}

\author{
Putri Septi Pratiwi \\ UIN Walisongo Semarang \\ Putri_1908096011@student.walisongo.ac.id \\ Mia Putri Seytawati \\ UIN Walisongo Semarang \\ Putri_1908096014@student.walisongo.ac.id
}

Ahmad Fauzan Hidayatullah
UIN Walisongo Semarang
afhidayatullah@walisongo.ac.id

Ismail

UIN Walisongo Semarang

ismail@walisongo.ac.id

\section{Tafsir}

UIN Walisongo Semarang

tafsir@walisongo.ac.id

\begin{abstract}
This article is prepared to examine some of the references as a foundation for describes the influence of social media as a medium for campaigning related to religious moderation movements and conceptualizes the form of the use of Instagram and Tiktok social media in campaigning for religious moderation movements. The method used in the preparation of this journal is qualitative descriptive combined with literature review research on related sources and journals, the research approach used is a field study, with a focus on the study of Instagram and Tik. Tok content. Religious moderation is a moderate view or attitude to try to take a neutral or middle position against the diversity of beliefs. With the existence of religious moderation, it is hoped that a balance in religion will be created. To strengthen religious moderation, various strategies can be carried out, one of the strata is the socialization of ideas, understanding, and education regarding religious moderation to the whole society. Because of this, the campaign regarding the religious moderation movement must be carried out massively and synergistically, especially on social media, especially Instagram and TikTok, which are social media services that are currently popular recently. By utilizing the popularity of social media networking services, it is hoped that the campaign against the religious moderation movement will be well received by
\end{abstract}

Jurnal Dakwah dan Komunikasi

IAIN Curup-Bengkulu |E-ISSN: 2548-3366; P-ISSN: 2548-3293 
84 Jurnal Dakwah dan Komunikasi, Vol.6 No.1, 2021

the public. Because of this, the campaign regarding the religious moderation movement must be carried out massively and synergistically, especially on social media, especially Instagram and TikTok, which are social media services that are currently popular recently. By utilizing the popularity of social media networking services, it is hoped that the campaign against the religious moderation movement will be well received by the public. Because of this, the campaign regarding the religious moderation movement must be carried out massively and synergistically, especially on social media, especially Instagram and TikTok, which are social media services that are currently popular recently. By utilizing the popularity of social media networking services, it is hoped that the campaign against the religious moderation movement will be well received by the public.

Keywords: Religious Moderation, Social Media, Instagram, Tik-Tok.

\begin{abstract}
Abstrak
Artikel ini disusun bertujuan untuk menelaah beberapa referensi sebagai pondasi untuk menjabarkan mengenai pengaruh dari media sosial sebagai media untuk berkampanye terkait gerakan moderasi beragama dan mengkonsepsi terkait bentuk dari pemanfaatan media sosial instagram dan tiktok dalam mengkampanyekan gerakan moderasi beragama. Metode yang digunakan dalam penyusunan jurnal ini adalah deskriptif kualitatif dengan dikombinasikan penelitian kajian literatur tehadap sumber dan jurnal terkait, pendekatan penelitian yang digunakan adalah studi lapangan, dengan fokus kajian pada konten instagram dan tik tok. Moderasi beragama merupakan pandangan yang moderat atau sikap untuk berusaha mengambil posisi netral atau ditengah terhadap adanya kebergaman kepercayaan. Dengan adanya moderasi beragama diharapkan akan tercipta keseimbangan dalam beragama. Untuk menguatkan moderasi beragama dapat dilakukan dengan berbagai strategi, salab satu strarateginya adalah sosialisasi terbadap gagasan, pemahaman, dan pendidikan mengenai moderasi beragama kepada seluruh masyarakat. Karena hal tersebut kampanye mengenai gerakan moderasi beragama harus dilaksanakan secara masif dan sinergis terutama di media sosial khususnya instagram dan tiktok yang merupakan layanan media sosial yang sedang populer belakangan ini. Dengan memanfaatkan kepopuleran layanan jejaring media sosial tersebut diharapkan kampanye terhadap gerakan moderasi beragama dapat diterima secara baik oleh masyarakat.
\end{abstract}

Kata Kunci: Moderasi Beragama, Media Sosial, Instagram, Tik-Tok. 


\section{Pendahuluan}

Moderasi beragama memiliki arti pengurangan kekerasan dan menghindari ekstremisme. ${ }^{1}$ Moderasi beragama juga dapat diartikan sebagai pandangan yang moderat terhadap adanya keberagaman. Hal tersebut sebagai upaya untuk mengakomodasi keberagaman agama yang ada di Indonesia. ${ }^{2}$ Dasar dari moderasi beragama yaitu memberikan ruang kepada agama yang telah diyakini oleh orang lain dan percaya terhadap doktrin agama yang absolut. ${ }^{3}$ Dalam arti lain moderasi beragama yaitu sikap ataupun pandangan untuk berusaha mengambil posisi netral atau ditengah antara dua pandangan. ${ }^{4}$ Serta sikap untuk selalu berupaya saling mendengarkan dan melatih kemampuan untuk mengatasi perbedaan. ${ }^{5}$

Moderasi beragama menghasilkan keseimbangan dalam praktik beragama dan dapat menjauhkan diri dari sikap berlebihan, revolusioner, dan fanatik dalam beragama. ${ }^{6}$ Keberagaman di negeri ini juga dapat berkembang dengan adanya moderasi beragama. Hal tersebut dikarenakan faktor kultur masyarakat yang majemuk sehingga cocok untuk digunakan di Indonesia.

Moderasi beragama sudah lama diterapkan di Indonesia. ${ }^{7}$ Terbukti dengan kepercayaan yang ada dan diakui di Indonesia semuanya mengenal apa itu moderasi beragama. Seperti pada ajaran agama Islam terdapat penjelasan konsep mengenai washatiyah yang bermakna sepadan atau sama dengan tawasuth yang memiliki arti tengah tengah, i'tidal yang memiliki arti adil, dan tawazun yang memiliki arti berimbang. ${ }^{8}$ Sedangkan dalam umat Kristen, arti dari moderasi beragama yaitu cara pandang untuk dapat mengetahui ekstrimisme terkait dengan tafsir terhadap ajaran agama Kristen dimana ajaran tersebut dipahami oleh sebagian umat Kristen.? Selain itu dalam persepektif Gereja Katolik moderasi beragama yang memiliki istilah "moderat" yang biasa yakni "terbuka"

${ }^{1}$ Ulfatul Husna and Muhammad Thohir, "Religious Moderation as a New Approach to Learning Islamic Religious Education in Schools," Nadwa 14, no. 1 (2020): 1999.

${ }^{2}$ Busyro, Aditiya Hari Ananda, and Adlan Sanur Tarihoran, "MODERASI ISLAM (WASATHIYYAH) DI TENGAH PLURALISME AGAMA INDONESIA," FUADUNA: Jurnal Kajian Kagamaan dan Kemasyarakatan 03, no. 01 (2019): 4354, https://ejournal.iainbukittinggi.ac.id/index.php/fuaduna/index.

${ }^{3}$ Fadhliah Mubakkirah, "MODERASI ISLAM: DARI KONSEP MENUJU IDENTITAS,” Bilancia: Jurnal Studi Ilmu Syariah dan Hukum (2018).

${ }^{4}$ Zuhairi Misrawi, "Kesadaran Multikultural Dan Deradikalisasi Pendidikan Islam: Pengalaman Bhinneka Tunggal Ika Dan Qabul Al-Akhar," Jurnal Pendidikan Islam 2, no. 1 (2013): 197.

${ }^{5}$ Lukman Hakim Saifuddin and Mentri Agama Republik Indonesia, "MODERASI UNTUK KEBERSAMAAN UMAT: Memaknai Rapat Kerja Nasional Kemenag 2019" https://jateng.kemenag.go.id/warta/download/1548283699.pdf.

(n.d.),

${ }^{6}$ Edy Sutrisno, "Aktualisasi Moderasi Beragama Di Lembaga Pendidikan," Jurnal Bimas Islam (2019).

${ }^{7}$ Edy Sutrisno.

${ }^{8}$ Penyusun kementrian Agama RI, Moderasi Beragama, Kementerian Agama, 2019.

${ }^{9}$ Sutrisno, "Aktualisasi Moderasi Beragama Di Lembaga Pendidikan." 
kepada "fundamentalis" serta "tradisional" atau membantah terhadap modernisasi menurut Gereja Katolik. ${ }^{10}$ Pada ajaran agama Hindu yang terpenting dalam moderasi beragama yaitu susila atau bagaimana upaya dalam menjalin hubungan harmonis antar manusia yang termasuk di dalam tiga penyebab kesejahteraan. ${ }^{11}$ Dalam agama Buddha terdapatSidharta Gautama yang menerangkantentangmoderasiberagama. Sidharta Gautama menetapkan empat prasetya, empat prasetya itu adalah pertama berusaha untuk menolong sesama makhluk; Kedua menolak semua nafsu duniawi; ketiga mengamati, mempelajari,d an mengamalkan Dharma; kelima berusaha untuk mencapai pencerahan yang sempurna. ${ }^{12}$ Dalam ajaran agama Khonghucu. Umat yang memiliki junzi (budi luhur) memandang hidup dalam kacamata yin yang, dikarenakan filosofi yin merupakan ideologi dan spiritual dari penganut kepercayaan Khonghucu yang hendaktinggal didalam dao.Sementara yin dan yang bukanlahsesuatu yang eksesif melainkan suatu bentuk penyelesaian. ${ }^{13}$

Menurut Masykuri Abdillah moderasi beragama menjadi kunci terciptanya kerukunan dan toleransi antar umat beragama. Dengan moderasi beragama umat beragama dapat menerima keberagaman dan saling menghormati sehingga dapat hidup dengan damai. Karena hal tersebut moderasi beragama bukanlah pilihan melainkan sebuah keharusan untuk diterapkan di Indonesia. ${ }^{14}$

Dalam menguatkan moderasi beragama terdapat tiga strategi utama, yaitu: pertama pelembagaan terkait moderasi beragama dalam kebijakan dan program yang mengikat; kedua sosialisasi terhadap gagasan, pemahaman, dan pendidikan mengenai moderasi beragama kepada seluruh masyarakat; ketiga mengintegrasi rumusan kedalam Rencana Pembangnan Jangka Menengah Nasional(RPJMN) tahun 2020 sampai tahun 2024. ${ }^{15}$

Strategi gerakan moderasi beragama dengan sosialisasi terhadap gagasan, pemahaman, dan pendidikan mengenai moderasi beragama kepada seluruh masyarakat dapat dilakukan dengan melakukan kampanye-kampanye gerakan moderasi beragama. Kampanye tersebut dapat dilakukan dengan memanfaatkan media sosial. Dimana pada saat ini media sosial menjadi ruang yang sering didatangi orang Indonesia untuk belajar lebih banyak tentang agama. Media sosial sendiri merupakan inovasi teknologi informasi yang popular digunakan saat ini. Dengan penggunaan media sosial seseorang dapat dimudahkan untukmencariinformasidengansangatfleksibeldanadaptif. ${ }^{16}$

Karena hal tersebut kampanye mengenai gerakan moderasi beragama harus dilaksanakan secara masif dan sinergis terutama di media sosial khususnya instagram dan tiktok yang merupakan layanan media sosial yang sedang populer

${ }^{10}$ Sutrisno

${ }^{11}$ Sutrisno.

${ }^{12}$ Sutrisno.

${ }^{13}$ Penyusun kementrian Agama RI, Moderasi Beragama.

${ }^{14}$ Sutrisno, "Aktualisasi Moderasi Beragama Di Lembaga Pendidikan."

${ }^{15}$ Penyusun kementrian Agama RI, Moderasi Beragama.

${ }^{16}$ Rahmatul Jannatin Naimah, Ahmad Rifani, and Riza Firdaus, "Analisis Penerapan Relationship Maintenance Strategy Melalui Penggunaan Media Sosial ( Studi Pada Twitter Perbankan Di Indonesia )," Jurnal Wawasan Manajemen vol.1 (2013): 153-166. 
belakangan ini. Dengan memanfaatkan kepopuleran layanan jejaring media tersebut diharapkan kampanye terhadap gerakan moderasi beragama dapat diterima secara ba.ik oleh masyarakat.

Pertanyaannya, seperti apa bentuk konten sosialisasi yang berisikan gagasan, pemahaman, dan pendidikan mengenai moderasi beragama yang dianggap tepat guna mengkampanyekan terkait gerakan moderasi beragama melalui media sosial, terutama pada media sosial Instagram dan Tiktok?

Penelitian metode Kualitatif dan pendekatan studi lapangan digunakan untuk mempertimbangkan tujuan penelitian yaitu untuk mengetahuipengaruh konten dalam media sosial Instagram dan Tiktok dalam upaya kampanye gerakan moderasi beragama serta untuk mengkonsepsi bentuk pemanfaatan dari media sosial Instagram dan Tiktok dalam kampanye moderasi beragama di Indonesia.Fungsi daripenggunaan metode ini karena peneliti ingin menjelaskan terkait bentuk dari pemanfaatan media sosial instagram dan tiktok sebagai media kampanye gerakan moderasi beragama dengan mengkaji terkait elemen foto dan video pada aplikasi Instagram dan Tiktok. Dengan menggunakan tahapan pencarian terhadap literatur dan interpretasi data pada artikel maupun penelitian yang terakait serta konten yang terdapat dalam media sosial instagram dan tiktok yang menggunakan tagar \#moderasiberagama.

\section{Hasil dan Pembahasan}

\section{Pengaruh Penggunaan Media Sosial Sebagai Media Kampanye Gerakan Moderasi Beragama}

Perkembangan Teknologi Informasi mendorong tumbuhnya mediamedia baru. Media baru tersebut berupa teknologi komunikasi digital yang saling terkoneksi dalam satu jaringan. Media baru tersebut dapat digunakan untuk menyalurkan informasi kepada penerima. ${ }^{17}$ Media baru juga dapat mempengaruhi level dan cara berpikir masyarakat modern ${ }^{18}$ Media baru yang dimaksud tersebut adalah media sosial.

Perkembangan interaksi dan budaya komunikasi pada masarakat merupakan dampak dari adanya media sosial. Masyarakat tidak lagi hanya bisa berinterkasi secara nyata atau interaksi sosial dengan tatap muka tetapi juga dapat terhubung secara maya atau tidak bisa ditangkap menggunakan indrawi dengan langsung tetapi bisa dirasakanmelalui teknologi digital. ${ }^{19}$

\footnotetext{
${ }^{17}$ Agus Efendi, Puwani Indri Astuti, and Nuryani Tri Rahayu, "ANALISIS PENGARUH PENGGUNAAN MEDIA BARU TERHADAP POLA INTERAKSI SOSIAL ANAK DI KABUPATEN SUKOHARJO," Jurnal Penelitian Humaniora (2017).

${ }^{18}$ S. Dinar Annisa Abdullah and Samudera Alfatra, "Narration of Islamic Moderation: Counter over Negative Content on Social Media," Millati: Journal of Islamic Studies and Humanities (2019).

${ }^{19}$ Ari Wibowo, "Kampanye Moderasi Beragama Di Facebook: Bentuk Dan Strategi Pesan,” Edugama: Jurnal Kependidikan dan Sosial Keagamaan 5, no. vol.5 No.1 (2019).
} 
Media sosial sering digunakan orang Indonesia sebagai ruang untuk belajar mengenai agama. ${ }^{20}$ Media sosial memiliki kelebihan dalam interaksi dan koneksi online sperti memiliki aksesbilitas, kecepatan, interaktivitas, umur panjang dan jangkauan sehingga membuatnya lebih kuat daripada media tradisioanal. ${ }^{21}$ Dalam berinteraksi para pengguna menggunakan media sosial dengan menciptakan konten atau informasi yang tersedia dalam media atau produk elektronik. ${ }^{22}$

Dalam kampanye moderasi beragama penggunaan media sosial memiliki pengaruh yang sangat kuat. Hasil penelitian yang dilakukan oleh Natalie Stroud mengemukakan bahwa peran media yaitu, untuk mencuri perhatian dari pengguna yang menggunakan media sosial lewat konten-konten yang telah dibagikan dalam media sosial. ${ }^{23} \mathrm{Di}$ bawah pengaruhnya, media sosial dikenal sebagai penggerak gerakan atau kekuatan rakyat. Media sosial telah memainkan peran penting dalam menarik pendukung melalui berbagai rilis informasi. ${ }^{24}$ Berdasarkan ini lah, media sosial dapat dimanfaatkan sebagai media kampanye moderasi beragama karena pengaruhnya yang dapat mencuriperhatiandari pengguna media sosial melalui konten-konten yang dibuat dandibagikan sebagai pendorong pergerakan atau people power sehingga diharapkan dapat mengubah sikap dan perilaku masyarakat untuk saling menghormati dan dapat menerima keberagaman sesuai dengan konteks moderasi beragama.

\section{Bentuk Kampanye Moderasi Beragama di Instagram dan Tiktok}

Instagram adalah aplikasi yang baru muncul di dunia maya tetapi sudah bisa memikat sebagian orang untuk menggunakan aplikasi instagram. Didalam instagram terdapat fitur untuk mengupload foto, video, atau igtv, dan juga bisa melakukan siaran langsung (live ig). Instagram juga seperti aplikasi lainnya contohnya facebook. Jika kita mengupload sesuatu di instagram contohnya foto, video atau punig tv kita bisa memberikan hastag agar bisa dilihat oleh orang banyak. ${ }^{25}$

${ }^{20}$ Satrio Dwicahyo, "Muslim Preachers in Social Media: Fighting For Moderation," RSIS COMMENTARY, no. 187 (2017), www.rsis.edu.sg.

${ }^{21}$ R R Wuri Arenggoasih and Corona Raisa Wijayanti, "Pesan Kementerian Agama Dalam Moderasi Melalui,” Jurnal Jurusan Jurnalistik 06 (2020): 160-176.

${ }^{22}$ Aziz Reza Randisa and Achmad Nurmandi, “Analisis Konten Media Sosial Twitter Sarana Pendidikan Di Indonesia Study Kasus Ruang Guru,” Jurnal Ilmiah Tata Sejuta STIA Mataram 6, no. 2 (2020): 291-601.

${ }^{23}$ Artika Sari, "Media Sosial Dan Pengaruhnya Terhadap Proses Pemilihan Umum," Tirto.Id, last modified 2019, accessed November 11, 2020, https://tirto.id/dhks.

${ }^{24}$ Jonathan Patrick, "People Power, Kekuatan Medsos, Dan Pengaruh Media Daring," CNN Indonesia, last modified 2019, accessed November 30, 2020, https://www.cnnindonesia.com/teknologi/20190523110545-185-397733/peoplepower-kekuatan-medsos-dan-pengaruh-media-daring. Melalui."

${ }^{25}$ Arenggoasih and Wijayanti, "Pesan Kementerian Agama Dalam Moderasi 
Berbeda dengan media sosial Instagram, media social Tiktok baru justru baru populer padaakhir - akhirini. Aplikasi TikTok sendiri telah menjadi aplikasi media sosial yang populer diunduh dari playstore, yakni sebanyak 1 miliar kali unduhan pada bulan Maret 2020.26itur yang ditawarkan Tiktok adalah pengguna dapat membuat video durasi pendek dengan menggunakan suara yang mereka buat sendiri atau menggunakan suara yang telah disediakan oleh aplikasi.

Media sosial Instagram dan Tiktok memiliki banyak fitur yang sama, salah satunya adalah fitur tagar dengan simbol “\#”. Fitur tagar adalah fitur yang berfungsi untuk mengelompokan konten yang telah dibuat. Dengan menyertakan tagar pada postingan maka postingan tersebut akan dikelompokan dan terorganisir dengan baik. ${ }^{27}$ Komponen yang harus diperhatikan pada media sosial instagram dan tiktok agar menjadi trending adalahfotoataugambar yang mempunyaikualitas bagus, video yang tidak blur, caption yang menggambarkan apa yang ada di dalam foto dan video, dan juga tagar untuk menjangkau orang banyak. Komponen itu sangat berpengaruh terhadap like, komen dan jangkauan orang banyak. Semakin kita menshare atau mengupload foto atau video yang bermanfaat atau positif Semakin banyak juga orang yang like dan komen. ${ }^{28}$

Pengertian dari kampanye sendiri merupakan bentuk dari komunikasi yang memiliki sifat verbal dan non verbal yang berarti pesan yang disampaikan didalam bentuk gambar dan video dapat tersampaikan dengan baik kepada pengguna lainnya. ${ }^{29}$ Pada umumnya penggunaan istilah kampanye lebih kepada komunikasi yang berbau politik yang biasanya muncul disaat pemilihan umum.

Kemudian Charles U. Larson membagi kampanye menjadi beberapa jenis sesuaidengan fungsinya, yaitu; 1) candidate-oriented; 2) product-oriented; dan 3)ideologically-oriented. ${ }^{30}$ Kampanye yang dilakukan denganIdeologically or Cause Orientedatauberorientasiterhadap ideology inidapatdilakukansebagaikampanye gerakan moderasi beragama, kampanye jenis ini dianggap mampu untuk menangani masalah-masalah sosial yang

${ }^{26}$ Adam Rizal, "Diunduh 1 Miliar Kali, Pengguna TikTok Melonjak Selama Pandemi Corona," Infokomputer.Grid.Id, last modified 2020, accessed November 30, 2020, https://infokomputer.grid.id/read/122107347/diunduh-1-miliar-kali-penggunatiktok-melonjak-selama-pandemi-corona.

${ }^{27}$ Merlion Gusti, "Ini Fungsi Dan Kegunaan Hashtag Atau Tagar Di Media Sosial," Kompas.Tv, last modified 2020, accessed November 30, 2020, https://www.kompas.tv/article/100414/fungsi-dan-kegunaan-hastag-atau-tagar-dimedia-sosial\#: :text=Hashtag atau tagar bisa digunakan,terorganisir dan terkelompok dengan baik.

${ }^{28}$ Edwin Adrianta Surijah et al., "MEMBEDAH INSTAGRAM: ANALISIS ISI MEDIA SOSIAL PARIWISATA BALI," Intuisi Jurnal Psikologi Ilmiah 9, no. 1 (2017): 26-38, http://journal.unnes.ac.id/nju/index.php/INTUISI\%0AMEMBEDAH. Media, 2010).

${ }^{29}$ Antar Venus, Manajemen Kampanye (Bandung: Simbiosa Rekatama

${ }^{30}$ Rosady Ruslan, Manajemen Public Relations Dan Media Komunikasi, Rajawali Pers, 2012. 
ada di masyarakat, contohnya perubahan dari perilaku, sikap,dan pandangan dari masyarakat.

Selain itu, kampanye dengan jenis ideologically-oriented perlu untuk ditingkatkan menggunakan bentuk kegiatan yang memiliki interaksi simbolik. Interaksi simbolik memiliki konsep sesuai dengan pemikiran Mead. Tiga konsep dasar terkait interaksi simbolik,yaitu: pertama mind atau pikiran yang merupakan kemampuan mengatur simbol dengan makna sosial yang sama. Dengan kata lain, setiap orang mengembangkan pemikirannya sendiri saat berinteraksi dengan orang lain; ${ }^{31}$ Kedua, Personal Self, yaitu kemampuan memahami diri masing-masing dalam sudut pandangdariorang lain;Ketiga,masyarakat, yaitu interaksi yang diselenggarakan oleh setiap orang dalam masyarakat, dan masyarakat berpartisipasi aktif di dalamnya. ${ }^{32}$ Karena hal tersebut, proses terkait gerakan kampanye moderasi beragama dalam media sosial instagram dan tiktok dapatdilakukan oleh siapa saja.

Ada beberapa potret kampanye moderasi beragama di instagram dan tiktok yang memanfaatkan tagar \#moderasiberagama. Pada laman cari di instagram maupun Tiktok, lebih banyak pengguna yang mempublish gagasan moderasiberagama di media sosial instagram daripada pengguna media sosial di tiktok. Seperti dalam gambar berikut ini:

Gambar 1. Bentuk kampanyegerakan moderasiberagama di Instagram

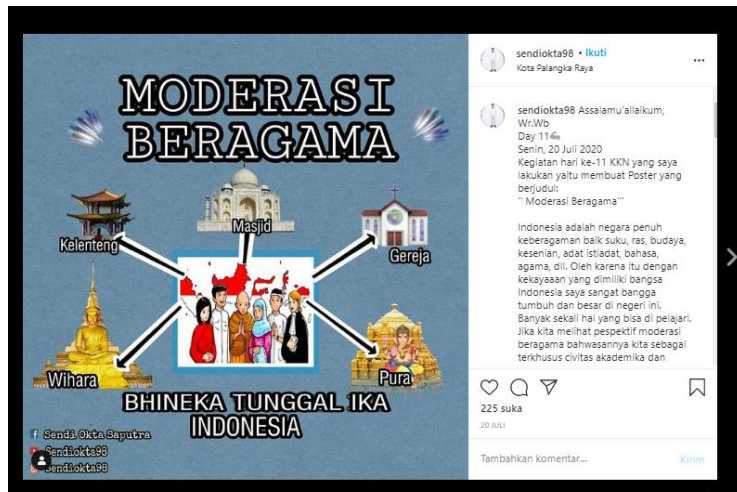

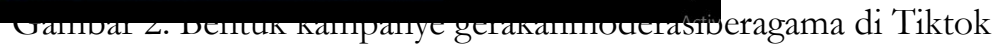

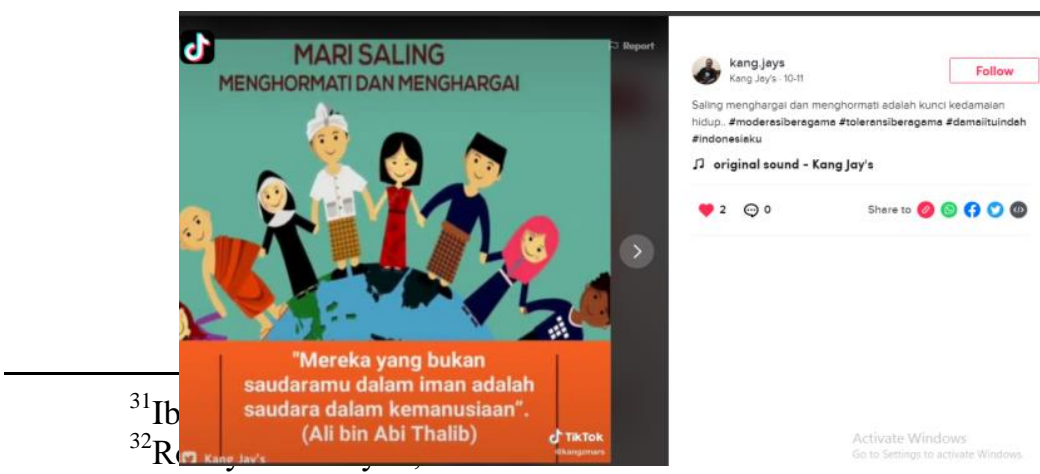

(CYBER): SUATU PROSES INTERAKSI SIMBOLIK," Sosial Budaya (2017). 
Akun Instagram @sendiokta98 dan Tiktok @kang.jays tersebut mengkampanyekan moderasi beragama lewat poster dan video pendek yang bermuatan nilai-nilai moderasiberagama. Di dalam kampanye, pesan yang terkandung di dalam nya sangat penting, karena dapat menunjang keberhasilan dari kampanye tersebut. Dalam akun @sendiokta98 ia menjelaskan bahwa Indonesia adalah negara yang penuh dengan keberagaman, baik itu keberagaman suku, bangsa maupun agama. Ia secara khusus mengkampanyekan moderasi beragama. Ia menjelaskan bahwa kita sebagai civitas akademika memiliki peran yang penting dalam melakukan kampanye ini. sedangkan dalam akun tik tok@kang.jays ia menyampaikan bahwa kuncidari kedamaian hidup adalah saling menghormati dan menghargai sesama. Pesan yang dibuat bisa dalam bentuk tulisan, yang berisikanlambang atau simbol yang sudah di sepakati sebelumnya. ${ }^{33}$ Pratikno menjelaskan terkait pesan, bahwa" pesan adalah segala bentuk komunikasi,baikverbal ataupun nonverbal". ${ }^{34}$ Verbal sendiri berarti komunikasi lewat lisan sedangkan nonverbal memiliki arti komunikasi menggunakanisyarat, sentuhan penciuman danperasaan, dan simbol.Menurut Hanafi terdapat tiga faktor yang menjadi pertimbangan dalam pesan, yaitu: pertama materi dalam pesan; kedua bentuk dari pesan; ketiga kode pesan. ${ }^{35}$

Dalam akun tersebut pengguna telah mengkampanyekan gerakan moderasi beragama terkait konten sosialisasi terhadap gagasan, pemahaman, dan pendidikan mengenai moderasi beragama dengan memposting poster dan video yang berisikan pesan dan simbol-simbol mengenai moderasi beragama. Pada postingan tersebut pengguna menggunakan simbol-simbol yang memiliki makna tentang moderasi beragama, simbol tersebut berupa perbedaan tempai ibadah dan pakaian yang biasa dipakai oleh penganut kepercayaan tersebut. Simbol tersebut dapat dimaknai sebagai perbedaan agama yang ada di Indonesia. Pengguna menuliskan materi pesan yang akan disampaikan melalui caption yang tertera pada postingan tersebut. Pesan dalam kampanye tersebut berbentuk pesan persuasif atau pesan yang berisi ajakan yang membangkitkan pemahaman dan kesadaran manusia terhadap apa yang disampaikan,yang akan mengubah sikap seseorang. ${ }^{36}$ Dalam kampanye tersebut pesan yang akan disampaikan telah dibuat dengan

${ }^{33}$ Onong Uchjana Effendy, Ilmu Komunikasi, Teori Dan Praktek, Komunikasi Dalam Sebuah Organisasi, 2009.

${ }^{34}$ Wibowo, "Kampanye Moderasi Beragama Di Facebook: Bentuk Dan Strategi Pesan."

${ }^{35}$ Wibowo.

${ }^{36}$ Wibowo. 
menarik dengan dikemas dalam bentuk poster dan video singkat, hal tersebut dimaksudkan agar pengguna lain dapat tertarik untuk melihat dan membacanya sehingga pesan dapat dilihat oleh banyak orang dan dapat membangkitkan pemahaman serta kesadaran dengan harapan mampu merubah sikap sesorang untuk sadar akan adanya moderasi beragama.

\section{Penutup}

Moderasi beragama merupakan pandangan yang moderat atau sikap untuk berusaha mengambil posisi netral atau ditengah terhad apa adanya kebergaman kepercayaan. Dengan adanya moderasi beragama maka akan tercipta keseimbangan beragama. Pengatan moderasi beragama dapat dilakukan dengan berbagai strategi, salah satu strarateginya adalah sosialisasi terhadap gagasan, pemahaman, dan pendidikan mengenai moderasi beragama untu kseluruh masyarakat. Strategi tersebut dapat dilakukan dengan kampanye-kampanye gerakan moderasi beragama. Kampanye tersebut dapat dilakukan dengan memanfaatkan media sosial. Dengan memanfaatkan kepopuleran layanan jejaring media tersebut diharapkan kampanye terhadap gerakan moderasi beragam adapat diterima secara baik oleh masyarakat. Dalam kampanye moderasi beragama penggunaan media sosial memiliki pengaruh yang sangat kuat. Dalam pengaruhnya media sosial dapat digunakan untuk menarik perhatian dari pengguna lewat konten yang telah dibuat dan dibagikan dalam media sosial dan dapat menjadi pendorong pergerakan atau people power sehingga diharapkan dapat mengubah sikap dan perilaku masyarakat untuk saling menghormati dan dapat menerima keberagaman sesuai dengan konteks moderasi beragama. Bentuk pemanfaatan media sosial instagram dan tiktok sebagai media dalam kampanye moderasi beragama dapat dilihat dalam penggunaan taggar \#moderasi beragama dalam kedua media sosial tersebut. Terdapat beberapa akun yang mengkampanyekan moderasi beragama. Salah dua diantaranya adalah @kang.jays dan@sendiokta98. Dalam kedua akun tersebut pengguna telah memposting poster dan video yang berisikan pesan dan simbol-simbol mengenai moderasi beragama. Pesan dalam kampanye tersebut berbentuk persuasif yang berisikan bujukanserta rayuanyang dapat meningkatkan kesadaran dan pengertian kepada penerima pesan bahwa apa yang disampaikan dalam pesan tersebut dapat merubah sikap dari sesorang terkait moderasi beragama.

\section{Daftar Pustaka}

Abdullah, S. Dinar Annisa, and Samudera Alfatra. "Narration of Islamic Moderation: Counter over Negative Content on Social Media." Millati: Journal of Islamic Studies and Humanities (2019).

Antar Venus. Manajemen Kampanye. Bandung: Simbiosa Rekatama Media, 2010.

Arenggoasih, R R Wuri, and Corona Raisa Wijayanti. "Pesan Kementerian Agama Dalam Moderasi Melalui." Jurnal Jurusan Jurnalistik. 06 (2020): 160_ 176. 
Busyro, Aditiya Hari Ananda, and Adlan Sanur Tarihoran. "MODERASI ISLAM (WASATHIYYAH) DI TENGAH PLURALISME AGAMA INDONESIA.” FUADUNA: Jurnal Kajian Kagamaan dan Kemasyarakatan 03, no. 01 (2019): 43-54. https:/ / ejournal.iainbukittinggi.ac.id/index.php/ fuaduna/index.

Cahyono, Anang Sugeng. "Pengaruh Media Sosial Terhadap Perubahan Sosial Masyarakat Di Indonesia." Jurnal ilmu sosial \& ilmu politik diterbitkan oleh Fakultas Ilmu Sosial \& Politik, Universitas Tulungagung (2016).

Dwicahyo, Satrio. "Muslim Preachers in Social Media: Fighting For Moderation."RSIS COMMENTARY, no. 187 (2017). www.rsis.edu.sg.

Efendi, Agus, Puwani Indri Astuti, and Nuryani Tri Rahayu. "ANALISIS PENGARUH PENGGUNAAN MEDIA BARU TERHADAP POLA INTERAKSI SOSIAL ANAK DI KABUPATEN SUKOHARJO.” Jurnal Penelitian Humaniora (2017).

Effendy, Onong Uchjana. Ilmu Komunikasi, Teori Dan Praktek. Komunikasi Dalam Sebuab Organisasi, 2009.

Gusti, Merlion. "Ini Fungsi Dan Kegunaan Hashtag Atau Tagar Di Media Sosial." Kompas.Tv. Last modified 2020. Accessed November 30, 2020. https://www.kompas.tv/article/100414/ fungsi-dan-kegunaan-hastag-atautagar-di-media-sosial\#: : :text=Hashtag atau tagar bisa digunakan,terorganisir dan terkelompok dengan baik.

Husna, Ulfatul, and Muhammad Thohir. "Religious Moderation as a New Approach to Learning Islamic Religious Education in Schools." Nadwa 14, no. 1 (2020): 1999.

Lukman Hakim Saifuddin, and Mentri Agama Republik Indonesia. "MODERASI UNTUK KEBERSAMAAN UMAT: Memaknai Rapat Kerja Nasional Kemenag 2019” (n.d.). https://jateng.kemenag.go.id/warta/download/1548283699.pdf.

Misrawi, Zuhairi. "Kesadaran Multikultural Dan Deradikalisasi Pendidikan Islam: Pengalaman Bhinneka Tunggal Ika Dan Qabul Al-Akhar." Jurnal Pendidikan Islam 2, no. 1 (2013): 197.

Mubakkirah, Fadhliah. "MODERASI ISLAM: DARI KONSEP MENUJU IDENTITAS.” Bilancia: Jurnal Studi Ilmu Syariah dan Hukum (2018).

Naimah, Rahmatul Jannatin, Ahmad Rifani, and Riza Firdaus. "Analisis Penerapan Relationship Maintenance Strategy Melalui Penggunaan Media Sosial ( Studi Pada Twitter Perbankan Di Indonesia )." Jurnal Wawasan Manajemen vol.1 (2013): 153-166.

Patrick, Jonathan. "People Power, Kekuatan Medsos, Dan Pengaruh Media Daring." CNN Indonesia. Last modified 2019. Accessed November 30, 2020. https://www.cnnindonesia.com/teknologi/20190523110545-185397733/people-power-kekuatan-medsos-dan-pengaruh-media-daring.

Penyusun kementrian Agama RI. Moderasi Beragama. Kementerian Agama, 2019.

Randisa, Aziz Reza, and Achmad Nurmandi. "Analisis Konten Media Sosial Twitter Sarana Pendidikan Di Indonesia Study Kasus Ruang Guru.” Jurnal Ilmiah Tata Sejuta STLA Mataram 6, no. 2 (2020): 291-601.

Rizal, Adam. "Diunduh 1 Miliar Kali, Pengguna TikTok Melonjak Selama Pandemi Corona." Infokomputer.Grid.Id. Last modified 2020. Accessed November 30 , 2020. https://infokomputer.grid.id/read/122107347/diunduh-1-miliar-kali- 
94 Jurnal Dakwah dan Komunikasi, Vol.6 No.1, 2021

pengguna-tiktok-melonjak-selama-pandemi-corona.

Rohayati, Rohayati. "BUDAYA KOMUNIKASI MASYARAKAT MAYA (CYBER): SUATU PROSES INTERAKSI SIMBOLIK.” Sosial Budaya (2017).

Ruslan, Rosady. Manajemen Public Relations Dan Media Komunikasi. Rajawali Pers, 2012.

Sari, Artika. "Media Sosial Dan Pengaruhnya Terhadap Proses Pemilihan Umum." Tirto.Id. Last modified 2019. Accessed November 11, 2020. https://tirto.id/dhks.

Soraya, Iin. "Strategi Kreatif Pesan Iklan Ladang Coffee Dalam Membangun Brand Image Sebagai Coffeeshop Khas Nusantara." Jurnal Komunikasi (2018).

Surijah, Edwin Adrianta, Cokorda Tesya Kirana, Ni Putu Julian Dian Wahyuni, Putu Chrisna Yudi, and Ni Komang Budi Astini. "MEMBEDAH INSTAGRAM: ANALISIS ISI MEDIA SOSIAL PARIWISATA BALI." Intuisi Jurnal Psikologi Ilmiah 9, no. 1 (2017): 26-38. http://journal.unnes.ac.id/nju/index.php/INTUISI\%0AMEMBEDAH.

Sutrisno, Edy. "Aktualisasi Moderasi Beragama Di Lembaga Pendidikan.” Jurnal Bimas Islam (2019).

Wibowo, Ari. "Kampanye Moderasi Beragama Di Facebook: Bentuk Dan Strategi Pesan." Edugama: Jurnal Kependidikan dan Sosial Keagamaan 5, no. vol.5 No.1 (2019). 